\title{
Community-acquired pneumonia in the elderly: Spanish multicentre study
}

\author{
R. Zalacain*, A. Torres\#, R. Celis", J. Blanquer", J. Aspa ${ }^{+}$, L. Esteban ${ }^{\S}$, R. Menéndez ${ }^{f}$, \\ R. Blanquer**, L. Borderías"\#, on behalf of the "Pneumonia in the elderly" working group, \\ Area de Tuberculosis e Infecciones Respiratorias
}

Community-acquired pneumonia in the elderly: Spanish multicentre study. R. Zalacain, A. Torres, R. Celis, J. Blanquer, J. Aspa, L. Esteban, R. Menéndez, R. Blanquer, L. Borderias, on behalf of the "Pneumonia in the elderly" working group, Area de Tuberculosis e Infecciones Respiratorias. (C) ERS Journals Ltd 2003.

ABSTRACT: Community-acquired pneumonia (CAP) in the elderly has increased as a consequence of an overall increase of the elderly population. A controversy about the aetiology and outcome of CAP in this population still exists and more epidemiological studies are needed.

A prospective, 12-month, multicentre study was carried out to assess the clinical characteristics, aetiology, evolution and prognostic factors of elderly patients ( $\geqslant 65 \mathrm{yrs}$ ) admitted to hospital for CAP. The study included 503 patients (age $76 \pm 7$ yrs).

The clinical picture lasted $\leqslant 5$ days in $318(63 \%)$ and the main clinical features were cough $(n=407,81 \%)$ and fever $(n=380,76 \%)$. Aetiological diagnosis was achieved in $199(40 \%)$ cases, with a definite diagnosis obtained in $164(33 \%)$. Of the 223 microorganisms isolated the main agents found were Streptococcus pneumoniae in $98(49 \%)$ and Haemophilus influenzae in $27(14 \%)$. A total of 53 patients died $(11 \%)$ and the multivariate analysis showed the following factors of bad prognosis: previous bed confinement, alteration in mental status, absence of chills, plasma creatinine $\geqslant 1.4 \mathrm{mg} \cdot \mathrm{dL}^{-1}$, oxygen tension in arterial blood/inspiratory oxygen fraction ratio $<200$ at the time of admission, and shock and renal failure during the evolution.

The results of this study may aid in the management of empiric antibiotic treatment in elderly patients with community-acquired pneumonia and the patients who have a greater probability of bad evolution may be identified based on the risk factors.

Eur Respir J 2003; 21: 294-302.
*Servicio de Neumología, Hospital de Cruces, Bilbao, ${ }^{\#}$ Servei de Pneumología i Allèrgia Respiratoria, Institu Clínic de Pneumologia i Cirurgía Torácica, Hospital Clinic, Barcelona, Unidad de Cuidados Intensivos Respiratorios, Hospital Clínico, Valencia,

${ }^{+}$Servicio de Neumología, Hospital La Princesa, Madrid, ${ }^{\S}$ Sección de Neumología, Hospital Mutua Terrassa, Barcelona, ${ }^{f}$ Servicio de Neumología, Hospital La Fé, Valencia, ${ }^{* *}$ Servicio de Neumología, Hospital Dr Peset, Valencia and \#\#ección de Neumología, Hospital San Jorge, Huesca, Spain.

Correspondence: A. Torres and R. Zalacain, Secretaría SEPAR (Area TIR), Balmes 68 Pral., 08007 Barcelona, Spain

Fax: 34934878509

E-mail: ssepar@separ.es

Keywords: Aetiology, clinical characteristics, community-acquired pneumonia, elderly, prognostic factors

Received: July 172002

Accepted after revision: October 15 2002

This study was sponsored by the "Area de Tuberculosis e Infecciones Respiratorias (TIR)", Sociedad Española de Neumología y Cirugía Torácica (SEPAR) and Aventis.
Community-acquired pneumonia (CAP) is a relatively frequent infectious disease with an incidence that ranges from 3-6 cases per 1,000 inhabitants per year [1]. This incidence is markedly greater in elderly patients $(\geqslant 65 \mathrm{yrs}$,) ranging from $25-40$ cases per 1,000 inhabitants per year [2]. CAP also has greater morbidity and mortality in the elderly population than in a younger population, although apart from age, the association of underlying diseases, a very common associated factor in the elderly, accounts in part for this increased morbid-mortality [3, 4]. Classically, the clinical presentation of CAP in the elderly has been described as quite subtle $[5,6]$, thereby leading to a delay in diagnosis and treatment. However, in some reports $[7,8]$ the clinical picture has been fundamentally acute with few variations with respect to younger patients. Although it is clear that Streptococcus pneumoniae is the most common aetiological agent, there are discrepancies in different studies regarding the true incidence of Gram-negative bacilli and Pseudomonas aeruginosa [5, 8-14]. Mortality also appears to be increased in this group of patients with CAP, with values ranging $15-35 \%$ [15] and there are few reports on the prognostic factors associated with the evolution of this disease $[8,11,13]$. However, importantly, most reports dealing specifically with elderly patients with CAP have included a relatively low number of cases.

Since the number of elderly persons in Spain represents an important population, $\sim 15 \%$ of the overall population [16], a prospective, multicentre study was undertaken by the current authors' group (Area de 
Tuberculosis e Infecciones Respiratorias) in elderly patients admitted to hospital for CAP, with the aim of determining the clinical characteristics, aetiology, evolution and prognostic factors of this disease in Spain.

\section{Methods}

\section{Patients}

A total of 503 consecutive patients, $\geqslant 65 \mathrm{yrs}$ in age, admitted to 16 Spanish hospitals for CAP from January 11997 to December 31 1997, were studied prospectively. CAP was defined when a new radiological infiltrate was identified with one of the major criteria or two of the minor criteria, as described previously [17], at the time of admission. The major criteria included cough, expectoration or fever $\left(\geqslant 37.8^{\circ} \mathrm{C}\right)$; and the minor criteria included dyspnoea, pleuritic pain, altered mental status, pulmonary consolidation on auscultation and leukocytosis $>12 \times 10^{9} \cdot \mathrm{L}^{-1}$. Patients were hospitalised according to the previously published recommendations of the Spanish Society of Pneumology [18]. The following patients were excluded from the study: those who had been previously admitted within the last month, immunosuppressed patients, those with acquired immunodeficiency syndrome or patients receiving chemotherapy or corticosteroids (equivalent doses of prednisone $\geqslant 20 \mathrm{mg} \cdot \mathrm{day}^{-1}$ ). Patients with clinical confirmation of an alternative diagnosis other than pneumonia were also excluded from the study. The patients were examined within the first $24 \mathrm{~h}$ of hospital arrival, as well as throughout hospital stay. The diagnostic methods used and the treatment administered depended on the attending physician. At 40 days a follow-up visit with clinical and radiological control and serological analysis (when possible) was carried out.

\section{Microbiology}

Two serial blood cultures $(n=486,97 \%)$ and serology $(n=413,82 \%$, acute illness single sample and $\mathrm{n}=342,68 \%$ acute and convalescent paired samples) were performed. Serological analysis included the following determinations: influenza $\mathrm{A}$ and $\mathrm{B}$ antibodies determined by complement binding, parainfluenza, adenovirus, syncitial respiratory virus, immunoglobulin (Ig)G versus Mycoplasma pneumoniae, Chlamydia psittaci and Coxiella burnetii, and IgG and $\mathrm{IgM}$ versus Chlamydia pneumoniae by indirect immunofluorescence. Legionella pneumophila (serotypes 1-6) were diagnosed using the indirect immunofluorescence technique to detect antibodies. Enzyme-linked immunosorbent assay (ELISA) was used to detect IgM in $M$. pneumoniae. A second serum sample was obtained on the control visit at 40 days when possible. A sputum sample was obtained in $403(80 \%)$ patients. Culture was only performed in good quality samples showing $\geqslant 25$ leukocytes per field and $<10$ epithelial cells per field $(\mathrm{n}=186,37 \%)$. Detection of the $L$. pneumophila (serotype 1) urinary antigen by ELISA was performed in $60(12 \%)$ cases. Pleural fluid culture was carried out in $48(10 \%)$ cases. Transthoracic aspiration puncture (TAP) $(\mathrm{n}=47,9 \%)$ and bronchoscopic protected specimen brushing (BPSB) $(n=88$, $17 \%$ ) were indicated according to the decision of the physician responsible for the patient.

Sputum, pleural fluid, TAP and BPSB samples were cultured in the following medium: blood agar, chocolate agar, Sabouraud agar, buffered charcoal yeast extract, thioglycolate broth and medium for anaerobes of the Center for Disease Control.

The aetiology of pneumonia was considered as definitive under the following conditions: 1) isolation of a pathogen in cultures of blood or pleural fluid; 2) four-fold increase in IgG titres with final titres for C. pneumoniae (IgG $\geqslant 1$ of 512$),$ C. psittaci $(\mathrm{IgG} \geqslant 1$ of 64), L. pneumophila (IgG $\geqslant 1$ of 128), C.burnetti (seroconversion) and respiratory virus (seroconversion); 3) increase of $\operatorname{IgM}$ titres for C. pneumoniae (IgM $\geqslant 1$ of 32$)$, C.burnetti (IgM $\geqslant 1$ of 80$)$, M.pneumoniae (any positive titre); 4) a single titre (IgG $\geqslant 1$ of 128) or a positive urinary antigen for $L$. pneumophila; 5 ) isolation of primary pathogens on respiratory samples; 6) growth of a microorganism in TAP cultures; and 7) isolation of a pathogen on BPSB samples in counts $\geqslant 1 \times 10^{3}$ colony forming units $\cdot \mathrm{mL}^{-1}$.

Valid samples of sputum growing a predominant microorganism were considered for a very probable bacteriological diagnosis [19].

\section{Data collection}

The data collected for each patient were divided into three groups: 1) clinical and sociodemographical data prior to admission; 2) clinical, exploratory, analytical and radiographical data at the time of admission; and 3) data obtained during the evolution of the process.

The data prior to admission included the following variables: age, sex, place of residence, grade of physical activity, bed confinement, smoking habits and alcohol consumption, swallowing disorders, number and type of associated diseases and previous antibiotic treatment.

At the time of admission the following variables were collected prospectively: duration of symptoms prior to diagnosis, clinical symptoms (chills, cough, expectoration and its type, pleuritic pain, dyspnoea, alteration in mental state, arthromyalgias), exploratory data (body temperature, presence of crepitations or consolidation on auscultation, respiratory rate, cardiac frequency, mean blood pressure), analytical data (leukocyte count, haematocrit, haemoglobin, platelet counts, creatinine, glucose, aspartate aminotransferase, alanine aminotransferase, alkaline phosphatase, sodium, potassium, proteins, albumin values and arterial $\mathrm{pH}$, oxygen tension in arterial blood $\left(\mathrm{Pa}_{\mathrm{a}} \mathrm{O}_{2}\right)$, carbon dioxide tension in arterial blood and the $\mathrm{Pa}_{2} \mathrm{O}_{2} /$ inspiratory oxygen fraction $\left(F \mathrm{I}, \mathrm{O}_{2}\right)$ ratio), radiographical data (number of lobes involved and type of consolidation, e.g. lobar, bronchopneumonia, segmentary (less than one lobe), bilateral involvement).

During the evolution of the disease the following 
variables were collected: admission to intensive care unit (ICU), shock, need for mechanical ventilation, development of renal failure, radiographic progression, empyema, cavitation, modification in empiric antibiotic treatment, length of hospital stay, length of antibiotic treatment and death.

\section{Other definitions}

Physical activity was evaluated according to the Karnofsky scale [20], considering the activity as good when the index was $\geqslant 80$. Patients were considered as confined to bed when they were in this situation for $\geqslant 50 \%$ of the time [21]. Previous antibiotic treatment was considered as any antibiotic treatment administered the 15 days prior to admission due to symptoms caused by this process. On evaluation of mental state at the time of admission, the opinion of relatives or nursing staff was taken into account in addition to patient's history. Shock was defined as any of the following criteria: systolic blood pressure $<90 \mathrm{mmHg}$, need for vasopressor drugs for $>4 \mathrm{~h}$, urinary output $<20 \mathrm{~mL} \cdot \mathrm{h}^{-1}$ for $>4 \mathrm{~h}$ or total urinary output $<80 \mathrm{~mL} \cdot \mathrm{h}^{-1}$ in $4 \mathrm{~h}$ without any other cause of justification [22]. Renal failure during the evolution was considered when a deterioration of renal function was present with a decrease in creatinine clearance leading to plasma creatinine values $>2.5 \mathrm{mg} \cdot \mathrm{dL}^{-1}$ [23]. Radiographical progression (progressive pneumonia) was defined as an increase in infiltrate size of $\geqslant 50 \%$ within the first $48 \mathrm{~h}$ of hospital admission [24].

\section{Statistical analysis}

The results are presented as mean \pm SD or alternatively $\mathrm{n}(\%)$. The Chi-squared test was used for univariate analysis or the Fisher's exact test when the variable of interest was categorical. The paired t-test was used when the variable was quantitative. Multivariate analysis was performed with logistic regression models including the variables demonstrating statistical significance on univariate analysis. All the first level interactions were tested, excluding the variables presenting interaction in the analysis. The level of significance for all the contrasts was established at $\alpha \leqslant 0.05$.

\section{Results}

\section{General characteristics and underlying diseases}

From January 11997 to December 31 1997, 503 elderly patients with CAP admitted to 16 Spanish hospitals were studied. The general characteristics and underlying diseases of these patients are shown in table 1 . The mean age was $76.3 \pm 7.3 \mathrm{yrs}$, with 169 $(34 \%)$ of the patients being $\geqslant 80$ yrs of age. A total of $329(65 \%)$ showed good physical activity established by the Karnofsky index $\geqslant 80$. A further $430(85 \%)$ had one or more underlying disease and $127(25 \%)$ had received some antibiotic treatment prior to hospital admission.
Table 1.-General characteristics of the population

$\begin{array}{lc}\text { Age yrs } & 76.3 \pm 7.3 \\ \text { Sex M:F } & 319: 184 \\ \text { Nursing home yes/no } & 30 / 473 \\ \text { Previous physical activity Karnofsky } & 78.1 \pm 18.1 \\ \text { Normal Karnofsky 100-80 } & 329(65) \\ \text { Decreased Karnofsky } \leqslant 70 & 174(35) \\ \text { Bed confinement } & 98(19) \\ \text { Smoking habit } & \\ \text { Nonsmokers } & 242(48) \\ \text { Smokers } & 60(12) \\ \text { Exsmokers } & 197(39) \\ \text { Packets per year } & 50.8 \pm 25.1 \\ \text { Alcohol habit } & 90(18) \\ \text { Alcohol intake g.day }{ }^{-1} & 54.9 \pm 35.6 \\ \text { Underlying diseases } & \\ \text { None } & 73(15) \\ \text { Cardiovascular } & 241(44) \\ \text { Respiratory } & 217(42) \\ \text { Metabolic } & 112(22) \\ \text { Neurological } & 81(16) \\ \text { Neoplastic } & 34(7)\end{array}$

Data are presented as mean \pm SD or $\mathrm{n}(\%)$. M: male; $\mathrm{F}$ : female.

\section{Clinical data}

The main clinical data on hospital admission are shown in table 2 . The clinical picture was considered acute and lasted $\leqslant 5$ days in 318 cases $(63 \%)$. The mean period of the clinical picture was $5.8 \pm 5.4$ days. Overall the most frequent symptoms were cough (407 cases $(81 \%))$ and dyspnoea (351 patients $(70 \%))$. Fever $\left(\geqslant 38^{\circ} \mathrm{C}\right)$ was observed in 380 patients $(76 \%)$. The association of cough, expectoration and pleural pain (typical clinical picture) was seen in 152 cases $(30 \%)$. An acute altered mental status was established in $26 \%$ of patients (130). No significant differences were found in any of the variables studied when patients were stratified according to age, sex, nursing home, prior physical activity or comorbidities (table 3 ). The main analytical and radiographical data are shown in table 4. Seven patients (1\%) presented leukopaenia

Table 2. - Main clinical data on admission

\begin{tabular}{lc}
\hline Cough & $407(81)$ \\
Fever $\geqslant 38^{\circ} \mathrm{C}$ & $380(76)$ \\
Dyspnoea & $351(70)$ \\
Expectoration & $331(66)$ \\
$\quad$ Mucoid & $93(18)$ \\
Mucopurulent & $110(22)$ \\
Purulent & $110(22)$ \\
Haemoptysis & $18(4)$ \\
Chills & $267(53)$ \\
Pleural pain & $218(43)$ \\
Asthenia & $194(39)$ \\
Altered mental state & $130(26)$ \\
Arthromyalgias & $95(19)$ \\
Headache & $76(15)$ \\
Mean temperature ${ }^{\circ} \mathrm{C}$ & $37.9 \pm 0.9$ \\
Mean systemic blood pressure $\mathrm{mmHg}^{-1}$ & $94.8 \pm 17.8$ \\
Respiratory rate respirations $\cdot \mathrm{min}^{-1}$ & $24.2 \pm 10.4$ \\
Cardiac frequency beats $\cdot \mathrm{min}^{-1}$ & $93.4 \pm 19.3$ \\
Crepitations & $397(79)$ \\
\hline
\end{tabular}

Data are presented as mean \pm SD or $\mathrm{n}(\%)$. 
Table 3. - Main clinical manifestations and their potential modifying factors

\begin{tabular}{|c|c|c|c|c|c|c|c|c|c|c|c|}
\hline & \multirow{2}{*}{$\begin{array}{c}\text { Subjects } \\
\mathrm{n}\end{array}$} & \multicolumn{2}{|c|}{ Age } & \multicolumn{2}{|c|}{ Sex } & \multicolumn{2}{|c|}{ Nursing residence } & \multicolumn{2}{|c|}{ Karnofsky } & \multicolumn{2}{|c|}{ Underlying diseases } \\
\hline & & $<80$ & $\geqslant 80$ & M & $\mathrm{F}$ & Yes & No & $80-100$ & $\leqslant 70$ & Yes & No \\
\hline Sub & & 33 & 16 & 3 & 18 & 3 & 47 & 32 & 17 & 43 & 7. \\
\hline Clin & 318 & $20(66)$ & $98(58)$ & $95(61)$ & $123(67)$ & $1(70)$ & $97(63)$ & $221(67)$ & 97( & $266(62)$ & 52( \\
\hline Cough & 407 & $295(72)$ & $112(66)$ & $283(89)$ & $124(67)$ & $27(90)$ & $380(80)$ & $278(84)$ & $129(74)$ & $346(80)$ & $61(84)$ \\
\hline Fever $\left(\geqslant 38^{\circ} \mathrm{C}\right)$ & 380 & $262(78)$ & $118(70)$ & $253(79)$ & $127(69)$ & $25(83)$ & $355(75)$ & $248(75)$ & $132(76)$ & 318 (74) & $62(85)$ \\
\hline & & (68) & 123( & $238(68)$ & $113(61)$ & 24 & 760 & $244(74)$ & 107 & 2) & $40(55)$ \\
\hline Expectoration & 331 & $(63)$ & $121(72)$ & $225(71)$ & $106(58)$ & 21( & 310( & 219 (67) & 112 & 287 (67) & $44(60)$ \\
\hline Chills & 267 & $194(58)$ & $73(43)$ & $178(49)$ & $89(59)$ & $14(47)$ & $253(53)$ & $194(59)$ & $73(42)$ & $218(51)$ & $49(67)$ \\
\hline Pleural pain & 218 & $162(49)$ & $56(33)$ & $122(38)$ & $96(52)$ & $13(43)$ & $205(43)$ & $135(41)$ & $83(48)$ & $174(41)$ & $44(60)$ \\
\hline
\end{tabular}

Data are presented as n (\%). M: male; F: female. All p-values were nonsignificant.

Table 4. - Analytical and radiological data on admission

\begin{tabular}{lc}
\hline Laboratory data & \\
Leukocytes $\times 10^{9} \mathrm{~L}^{-1}$ & $15.4 \pm 17.6$ \\
Band forms $\geqslant 3 \%$ & $297(59)$ \\
Haematocrit $\%$ & $40.1 \pm 6.8$ \\
$\mathrm{BUN} \mathrm{mg} \cdot \mathrm{dL}^{-1}$ & $55.3 \pm 36$ \\
Creatinine $\mathrm{mg} \cdot \mathrm{dL}^{-1}$ & $1.9 \pm 0.9$ \\
Sodium $\mathrm{mEq} \cdot \mathrm{L}^{-1}$ & $137.7 \pm 5.9$ \\
Potassium $\mathrm{mEq} \cdot \mathrm{L}^{-1}$ & $4.6 \pm 1.5$ \\
Albumin $\mathrm{g} \cdot \mathrm{L}^{-1}$ & $32.5 \pm 6.7$ \\
$\mathrm{ALAT} \mathrm{U} \cdot \mathrm{L}^{-1}$ & $53.2 \pm 296$ \\
$\mathrm{ASAT} \mathrm{U} \cdot \mathrm{L}^{-1}$ & $48.1 \pm 311$ \\
$P \mathrm{O}_{2}$ with $F \mathrm{I}, \mathrm{O}_{2} 21 \% \mathrm{mmHg}$ & $61.8 \pm 15.9$ \\
$P \mathrm{a}, \mathrm{O}_{2} / F \mathrm{I}, \mathrm{O}_{2}<200$ & $41(8)$ \\
$\mathrm{Radiographical}$ data & \\
Lobar & $267(53)$ \\
$\mathrm{Segmentary}$ & $118(23)$ \\
Bronchopneumonia & $62(12)$ \\
Bilateral & $56(11)$ \\
Cavitation & $9(2)$ \\
Pleural effusion & $60(12)$ \\
\hline
\end{tabular}

Data are presented as mean \pm SD or $\mathrm{n}(\%)$. BUN: blood urea nitrogen; ALAT: alanine aminotransferase; ASAT: aspartate aminotransferase; $\mathrm{PO}_{2}$ : oxygen tension; $\mathrm{FI}, \mathrm{O}_{2}$ : inspiratory oxygen fraction; $\mathrm{Pa}_{\mathrm{a}} \mathrm{O}_{2}$ : oxygen tension in arterial blood.

$\left(<4 \times 10^{9} \mathrm{~L}^{-1}\right)$ and $194(39 \%)$ had a leukocyte count $\geqslant 15 \times 10^{9} \mathrm{~L}^{-1}$. The mean creatinine value on admission was $1.9 \mathrm{mg} \cdot \mathrm{dL}^{-1}$, with 141 cases $(28 \%)$ showing values $\geqslant 1.4 \mathrm{mg} \cdot \mathrm{dL}^{-1}$. With regards to chest radiography, the infiltrate was predominantly alveolar, lobar (267 cases $(53 \%))$ or segmentary $(118(23 \%))$.

\section{Microbiological data}

Microbiological diagnosis was achieved in 199 cases $(40 \%)$, being definitive in $164(33 \%)$ and presumptive (with positive sputum culture as single sample) in 35 $(7 \%)$. A total of 223 microorganisms were isolated and these are shown in table 5 . In 24 cases $(5 \%)$ two microorganisms were considered causative. S. pneumoniae was the pathogen most frequently observed, with 98 isolations found in $49 \%$ of those cases bacteriologically diagnosed, followed by $H$. influenzae (27 cases, 14\%) and L. pneumophila (19 cases, 10\%). Forty $(20 \%)$ atypical microorganisms and viruses were detected. $P$. aeruginosa was isolated in 12 cases $(6 \%)$ and Gram-negative bacilli in another $12(6 \%)$. In patients from a nursing home residence, bacteriological diagnosis was achieved in 11 of 30 cases $(37 \%)$, with 13 microorganisms (five $S$. pneumoniae, two $C$. pneumoniae, one L. pneumophila, one $P$. aeruginosa, one Klebsiella pneumoniae, one Escherichia coli, one Staphylococcus aureus, one Streptococcus viridans). Of the 503 patients, $159(32 \%)$ had received some antibiotic treatment prior to undergoing diagnostic techniques. Sputum analysis was performed in 403 $(80 \%)$ cases and of these $186(46 \%)$ were of good quality and $71(38 \%)$ showed positive results. In 35 (7\%) cases the sputum culture was the only sample in which diagnosis was obtained corresponding to: $H$. influenzae $(\mathrm{n}=14), S$. pneumoniae $(\mathrm{n}=10), P$. aeruginosa $(\mathrm{n}=7)$, E. coli $(\mathrm{n}=2), K$. pneumoniae $(\mathrm{n}=1)$ and $S$. aureus $(n=1)$. Blood cultures were performed in $486(97 \%)$ patients and were positive in $79(16 \%)$. The detection of the Legionella antigen in urine was carried out in 60 $(12 \%)$ cases and was positive in $10(17 \%)$. The other nine cases of Legionella were diagnosed by paired serology and one of these cases was also diagnosed by a positive TAP culture. Serological analysis was undertaken in $413(82 \%)$ patients for acute illness single sample and in $342(68 \%)$ for acute and convalescent paired samples tests and was positive in $58(14 \%), 53$ $(11 \%)$ by seroconversion and in five $(3 \%)$ with a high acute titre. Invasive diagnostic methods were performed in 135 patients $(27 \%), 47(9 \%)$ TAP and 88 $(17 \%)$ BPSB, being positive in 13 TAP $(28 \%)$ and in 44 BPSB $(50 \%)$. In 48 cases with pleural effusion, pleural puncture was performed obtaining a positive culture in $10(21 \%)$.

\section{Treatment of pneumonia}

The mean length of antibiotic treatment administered was $14.6 \pm 7.1$ days. The antibiotics administered were as follows: third-generation cephalosporins in 279 patients $(55 \%)$, macrolides in $222(44 \%)$, aminopenicillins in $138(27 \%)$, second-generation cephalosporins in $61(12 \%)$, quinolones (ciprofloxacin) in 13 $(3 \%)$, aminoglycosides in $11(2 \%)$, clindamycin in 10 $(2 \%)$ and others in seven patients (1\%). Cephalosporin or aminopenicillin with a macrolide was given in 198 cases $(39 \%)$. Monotherapy was administered in 264 $(52 \%)$ patients as follows: third-generation cephalosporins in $151(30 \%)$, aminopenicillins in 92 (18\%), 
Table 5. - Microorganisms $(n=223)$ isolated in 199 patients and diagnostic methods used

\begin{tabular}{lccc}
\hline Microorganism & $\mathrm{n}$ & $\mathrm{D} / \mathrm{P}^{\#}$ & Definitive diagnostic methods \\
\hline Streptococcus pneumoniae & 98 & $88 / 10$ & $51 \mathrm{H}, 22 \mathrm{BPSB}, 4 \mathrm{PF}, 3 \mathrm{TAP}, 3 \mathrm{H}+\mathrm{TAP}, 4 \mathrm{H}+\mathrm{PF}, 1 \mathrm{H}+\mathrm{BPSB}$ \\
Haemophilus influenzae & 27 & $13 / 14$ & $2 \mathrm{H}, 9$ BPSB, 1 TAP, 1 H+BPSB \\
Legionella pneumophila & 19 & 19 & $8 \mathrm{~S}, 1 \mathrm{~A}, 9 \mathrm{~S}+\mathrm{A}, 1 \mathrm{~S}+\mathrm{TAP}$ \\
Chlamydia pneumoniae & 13 & 13 & $13 \mathrm{~S}$ \\
Pseudomonas aeruginosa & 12 & $5 / 7$ & $2 \mathrm{H}, 1 \mathrm{BPSB}, 1 \mathrm{TAP}, 1 \mathrm{H}+\mathrm{BPSB}$ \\
Coxiella burnetii & 11 & 11 & $11 \mathrm{~S}$ \\
Mycoplasma pneumoniae & 10 & 10 & $10 \mathrm{~S}$ \\
Escherichia coli & 9 & $7 / 2$ & $5 \mathrm{H}, 1 \mathrm{BPSB}, 1 \mathrm{H}+\mathrm{PF}$ \\
Staphylococcus aureus & 8 & $7 / 1$ & $4 \mathrm{H}, 2 \mathrm{H}+\mathrm{BPSB}, 1 \mathrm{H}+\mathrm{TAP}$ \\
Moraxella catarrhalis & 3 & 3 & $2 \mathrm{BPSB}, 1 \mathrm{TAP}$ \\
Influenza virus & 3 & 3 & $3 \mathrm{~S}$ \\
Parainfluenza virus & 3 & 3 & $3 \mathrm{~S}$ \\
Klebsiella pneumoniae & 2 & $1 / 1$ & $1 \mathrm{TAP}+\mathrm{PF}$ \\
Streptococcus viridans & 2 & 2 & $1 \mathrm{TAP}, 1 \mathrm{H}+\mathrm{BPSB}$ \\
Serratia & 1 & 1 & $1 \mathrm{BPSB}$ \\
Enterococcus faecalis & 1 & 1 & $1 \mathrm{BPSB}$ \\
Nocardia & 1 & 1 & $1 \mathrm{BPSB}$ \\
\end{tabular}

D: definitive; P: presumptive; H: haemoculture; BPSB: bronchoscopic protected specimen brush; PF: pleural fluid; TAP: transthoracic aspiration puncture; S: serology; A: Legionella antigen in urine. ${ }^{\#}$ : with positive sputum culture as single sample.

second-generation cephalosporins in $16(3 \%)$ and macrolides in $5(1 \%)$.

Antibiotic treatment was modified in 126 cases $(25 \%)$; in $61(12 \%)$ due to aetiological findings (in 23 $(5 \%)$ a microorganism which was not covered was observed and in $38(30 \%)$ treatment was simplified). The total rate of failure to empirical treatment was 49 of $503(10 \%)$. In 16 patients $(3 \%)$ antibiotics were modified because of intolerance.

The resistence of $S$. pneumoniae to penicillin was observed in 28 of $98(29 \%)$, with $12(12 \%)$ cases of intermediate resistance and 16 cases $(16 \%)$ of highlevel resistance. There were no differences when comparing sensitive to resistant cases and the presence or absence of prior antibiotic treatment, seven $(10 \%)$ versus three (11\%). Macrolides were only tested in 70 cases, showing resistances in 17 of them $(24 \%$ ) (four of them $(25 \%)$ previously treated with antibiotics).

\section{Evolution}

Of the 503 patients studied, the evolution was favourable in 450 cases $(89 \%)$ and 53 patients died $(11 \%)$. In these latter cases bacteriological diagnosis was achieved in $28(56 \%)$, with the following microorganisms found: $12 \mathrm{~S}$. Pneumoniae (two of them resistant to penicillin), five $P$. aeruginosa, four $H$. influenzae, two L. pneumophila, two C. pneumoniae, one $M$. pneumoniae, one $E$. coli, one $S$. aureus, one Enterococcus faecalis, one Nocardia, and two cases with two microorganisms corresponding to the association of $S$. pneumoniae and $H$. influenzae. There were no significant differences in the evolution when comparing the cases with microbiological diagnosis, 28 of $199(14 \%)$, with the patients in whom a diagnosis was not obtained, 25 of 304 (8\%). In mixed pneumonias the mortality was $8 \%$ and in cases with single aetiology $15 \%(\mathrm{p}=\mathrm{NS})$. Likewise, the isolation of a determined microorganism (including $S$. pneumoniae resistant to penicillin) was not associated with greater mortality.

Mortality was not different when different antibiotic treatments were analysed. When cephalosporins or aminopenicillins were given with macrolides, mortality was $12 \%$, with third-generation cephalosporins in monotherapy $9 \%$, with aminopenicillins $12 \%$, with second-generation cephalosporins $6 \%$, with other associations $10 \%$ and with macrolides in monotherapy $0 \%$, although only five patients received this type of monotherapy. The mean length of hospital stay was $11.2 \pm 7.8$ days. Thirty-eight patients $(8 \%)$ were admitted to the ICU, 13 of whom died $(34 \%)$, and $21(4 \%)$ required mechanical ventilation, nine of whom died $(43 \%)$. The complications evaluated were as follows: renal failure (66 cases, 13\%), shock (41 cases, 8\%), empyema (14 cases, 3\%) and disseminated intravascular coagulation (two patients, $0.4 \%$ ).

\section{Prognostic factors}

Table 6 shows the different variables with prognostic influence assessed in the univariate analysis. The following variables prior to hospital admission were associated with worse prognosis: age $\geqslant 80 \mathrm{yrs,} \mathrm{resi-}$ dence in nursing homes, Karnofsky index $<70$, bed confinement and the existence of neurological disease. Significant variables on admission associated with a worse prognosis were as follows: alteration in mental status, respiratory rate $\geqslant 35$ respirations $\cdot \mathrm{min}^{-1}$ and creatinine values $\geqslant 1.4 \mathrm{mg} \cdot \mathrm{dL}^{-1}$. On the contrary, the association of cough, expectoration and pleural pain, chills and a $P \mathrm{a}_{2} \mathrm{O}_{2} / F \mathrm{I}, \mathrm{O}_{2}$ ratio $\geqslant 200$ had a protector effect. During the evolution of the disease, a worse prognosis was associated with ICU admission, mechanical ventilation, shock, the development of renal failure and empyema. Mortality was not higher in those cases in whom the empiric antibiotic 
Table 6. - Univariate analysis of prognostic factors influencing patient outcome

\begin{tabular}{|c|c|c|c|c|c|}
\hline & Nonsurvivors $n$ & Survivors $\mathrm{n}$ & $\mathrm{RR}$ & $95 \% \mathrm{CI}$ & p-value \\
\hline Subjects & 53 & 450 & & & \\
\hline \multicolumn{6}{|l|}{ Variables prior admission } \\
\hline Age $\geqslant 80$ yrs & 25 & 144 & 1.89 & $1.06-3.37$ & 0.028 \\
\hline Nursing residence & 9 & 21 & 4.17 & $1.80-9.68$ & $<0.001$ \\
\hline Karnofsky $<70$ & 29 & 87 & 5.03 & $2.79-9.08$ & $<0.001$ \\
\hline Bed confinement & 28 & 70 & 6.26 & $3.42-11.43$ & $<0.001$ \\
\hline Neurological disease & 17 & 64 & 2.84 & $1.50-5.37$ & 0.012 \\
\hline \multicolumn{6}{|l|}{ Variables on admission } \\
\hline Cough, exp., pleural pain & 8 & 144 & 0.37 & $0.17-0.82$ & 0.014 \\
\hline Chills & 15 & 252 & 0.30 & $0.16-0.57$ & $<0.001$ \\
\hline Altered mental state & 29 & 101 & 4.16 & $2.32-7.46$ & $<0.001$ \\
\hline Respiratory rate $\geqslant 35$ & 15 & 41 & 3.96 & $1.99-7.86$ & $<0.001$ \\
\hline Creatinine $\geqslant 1.4 \mathrm{mg} \cdot \mathrm{dL}^{-1}$ & 29 & 112 & 3.75 & $2.08-6.76$ & $<0.001$ \\
\hline$P_{\mathrm{O}_{2}} / F_{1}, \mathrm{O}_{2} \geqslant 200$ & 39 & 400 & 0.21 & $0.10-0.43$ & $<0.001$ \\
\hline \multicolumn{6}{|l|}{ Evolutive variables } \\
\hline Shock & 16 & 25 & 25 & $11.9-52.3$ & $<0.001$ \\
\hline ICU & 13 & 25 & 5.8 & $2.72-12.1$ & $<0.001$ \\
\hline Mechanical ventilation & 9 & 12 & 7.6 & $3.03-19.1$ & $<0.001$ \\
\hline Renal failure & 28 & 38 & 12.6 & $6.63-23.8$ & $<0.001$ \\
\hline Empyema & 4 & 10 & 3.6 & $1.09-12.1$ & 0.034 \\
\hline
\end{tabular}

RR: relative risk; CI: confidence interval; exp.: expectoration; $P_{\mathrm{O}_{2}}$ : oxygen tension; $F \mathrm{I}, \mathrm{O}_{2}$ : inspiratory oxygen fraction; ICU: intensive care unit.

treatment was modified due to uncovered microorganisms or therapeutic failures.

Table 7 shows the relative risks and confidence intervals of the variables included in the multivariate analysis to evaluate the independent prognostic factors with influence on disease evolution. Respiratory rate and ICU were not included in the analysis because of problems of interaction with other variables. As shown in table 7 , previous bed confinement, altered mental status and creatinine values $\geqslant 1.4 \mathrm{mg} \cdot \mathrm{dL}^{-1}$ at the time of admission and the existence of shock or renal failure during disease evolution were independent risk factors associated with greater mortality. Conversely, the existence of chills and a $\mathrm{Pa}_{\mathrm{a}} \mathrm{O}_{2} / F \mathrm{I}, \mathrm{O}_{2}$

Table 7.-Multivariate analysis of prognostic factors influencing patient outcome

\begin{tabular}{|c|c|c|c|}
\hline Prognostic factors & $\mathrm{RR}$ & $95 \% \mathrm{CI}$ & p-value \\
\hline \multicolumn{4}{|l|}{ Previous variables } \\
\hline Bed confinement & 3.43 & $1.19-9.85$ & 0.021 \\
\hline Nursing residence & 1.70 & .64 & 0.295 \\
\hline Karnofsky $<70$ & 1.58 & $0.53-4.65$ & 0.404 \\
\hline Neurological diseases & 1.52 & $0.71-3.22$ & 0.274 \\
\hline Age $\geqslant 80$ yrs & 1.11 & $0.58-2.13$ & 0.740 \\
\hline \multicolumn{4}{|l|}{ Variables on admission } \\
\hline Creatinine $\geqslant 1.4 \mathrm{mg} \cdot \mathrm{dL}^{-1}$ & 3.82 & 2.0 & $<0.001$ \\
\hline Altered mental st & 2.50 & $1.31-7.22$ & 0.005 \\
\hline Cough, exp., pleural pain & 0.56 & $0.24-1.30$ & 0.180 \\
\hline Chills & 0.41 & $0.20-0.81$ & 0.010 \\
\hline $\mathrm{PO}_{2} / F_{1}, \mathrm{O}_{2} \geq$ & 0.29 & $0.12-0.68$ & 0.004 \\
\hline \multicolumn{4}{|l|}{ Evolutive variables } \\
\hline Shock & 8.13 & 7.36 & $<0.001$ \\
\hline Renal Failure & 11.84 & $5.35-26.23$ & $<0.001$ \\
\hline Mechanical ventilation & 4.61 & $0.92-23.10$ & 0.062 \\
\hline Empyema & 1.29 & $0.26-6.29$ & 0.747 \\
\hline
\end{tabular}

RR: relative risk; CI: confidence interval; exp.: expectoration; $\mathrm{PO}_{2}$ : oxygen tension; $\mathrm{Fi}_{\mathrm{i}} \mathrm{O}_{2}$ : inspiratory oxygen fraction. ratio $\geqslant 200$ were independent protective factors associated with a better prognosis.

\section{Discussion}

This study is one of the largest series of elderly patients with CAP in the literature. The main findings were as follows: 1) contrary to common ideas, the clinical picture was acute ( $\leqslant 5$ days) in $63 \%$ of the cases and that the main clinical respiratory data were present frequently ( $\geqslant 60 \%$ of the cases); 2$) S$. pneumoniae was the main aetiological agent observed, followed by $H$. influenzae and L. pneumophila. Some cases of Gram-negative enteric bacilli were also observed; 3) the mortality was relatively low, $11 \%$. Although several prognosis factors were identified, neither age nor comorbidity were factors of poor prognosis on multivariate analysis.

CAP is common among the elderly population, with an increasingly higher incidence due to the progressive aging of the population. In the current study, including 503 patients, the mean age was $76.3 \mathrm{yrs}$, $85 \%$ of the cases presented a chronic underlying disease and only $30(6 \%)$ of patients resided in a nursing home. These figures are very similar to those recently published in the USA, which studied 623,718 CAP patients $\geqslant 65 \mathrm{yrs}$ with a mean age of $77 \mathrm{yrs}$. In this study more than two-thirds of patients had an underlying disease and $\sim 4.3 \%$ were admitted from nursing homes [25].

The form of presentation of CAP in the elderly has been described classically as quite unspecific and subacute, with an absence of respiratory symptoms, fever in $40-60 \%$ of the cases and a characteristic alteration in mental state in $20-50 \%$ of patients $[3,5,6,9,26]$. Although this is the prerecognised presentation, in the current study it was found that the main respiratory 
symptoms were found in $>60 \%$ of cases with a previous clinical picture of $<5$ days in $63 \%$ and with $76 \%$ presenting fever. These data show a similar pattern to that found in studies considering younger patients [19, 27], although it must be noted that in $26 \%$ of this elderly population the characteristic alteration in mental state was present on admission. Thorax radiography in the present series demonstrated a predominance of lobar and segmentary infiltrates in $77 \%$ of the cases, which is very similar to that found in younger patients [28]. Interestingly and in contrast to common ideas, no clinical differences were found in relation to other factors that could modify the clinical presentation. These factors were age (6579 yrs and $>80$ yrs), nursing home, prior physical activity and the presence of comorbidities. The present findings have been confirmed in at least two other series [7,8], in which $77 \%$ and $56 \%$ of the cases, respectively, presented clinical manifestations that may be considered as typical. Moreover, in a comparative study [29] on clinical data in patients with bacteraemic pneumococcic pneumonia there were very few differences in these data between elderly patients and those $<65$ yrs.

$S$. pneumoniae was by far the microorganism most frequently found, being observed in $49 \%$ of the cases diagnosed, followed by $H$. influenzae and L. Pneumophila. These findings are in agreement with other series, although with a notably lower number of cases included [5, 8, 11, 13]. At the time of these previous studies in Spain the antipneumococcal vaccine was not routinely administered to the elderly population, and thus, this could explain the high incidence of $S$. pneumoniae in the present series. In addition no relationship could be found between $S$. pneumoniae resistant to antibiotics and the presence of prior antibiotic treatment and mortality. In the present series the high number of atypical microorganisms found ( $C$. pneumoniae, $M$. pneumoniae, C. burnetii,) is also of note. This supports the finding of $32 \%$ of atypical microorganisms found in another study in Spain [11] and challenges the idea that atypical microorganisms are infrequent in old patients with CAP $[5,10,12]$. In the current series, in which serology was almost systematically used, these pathogens represented $20 \%$ of the microbiological diagnoses. Conversely, the presence of other Gram-negative bacilli was found in $12 \%$ of cases. It has also been described previously that these pathogens may cause $10-30 \%$ of the CAP in the elderly [3, 10, 12], although in other series $[8,11]$ this proportion did not surpass $3 \%$, and in one series on severe CAP in the elderly admitted to the ICU [13] these microorganisms represented $16 \%$. It is possible, at least in the present study, that a relatively low number of cases of Gram-negative bacilli may be due to the low number of patients from nursing homes where the number of these cases is usually greater $[15,27]$.

Although treatment was not protocolised, the patients were mainly treated with third-generation cephalosporins or aminopenicillins with $\beta$-lactamase inhibitors, associated or not with macrolides. This policy is the same as recommended in several guidelines of CAP $[1,18,30]$. Antibiotic treatment was modified in $25 \%$ of the cases, but it should be noted that the change was only due to an uncovered bacteriological finding, therapeutic failure or intolerance in 88 cases $(17 \%)$. Thus, the current authors agree with empirical antibiotic used, as described in the present study. Using this strategy this study covered most of the microorganisms causing CAP in this series, including $S$. pneumoniae resistant to penicillin. $P$. aeruginosa was not an important problem in the current series, and the authors believe that antipseudomonal antibiotics do not have to be administered as a routine initial option in this population. Moreover, the modification of the antibiotic therapy was not associated with a poor prognosis. In addition, no differences in mortality were found when comparing patients treated with $\beta$-lactams alone or in combination with macrolides.

The mortality in the present study was relatively low $(11 \%)$, especially if compared with other studies in which mortality ranged from $15-35 \%[5,8,11]$. However, a recent study in the USA in a similar population showed a mortality of $11 \%$ [25]. In the present series the prognostic score described by FINE et al. [30] was not used because the study was designed and initiated before its publication. The criteria of hospital admission used were those published in the guidelines of the Spanish Society of Pneumology [18]. Accordingly, $85 \%$ of the patients had at least one comorbidity, increased mean values of respiratory rate, frequently altered renal function and in $26 \%$ of cases presenting an altered mental state. All these factors are indicators of the severity of the population reported here. It is possible that given the high presence of an acute clinical picture with fever and respiratory symptoms the diagnosis of pneumonia was not delayed and thus, treatment was rapidly initiated, thereby influencing the low number of complications observed and the relatively low mortality rate. The search for prognostic factors has been debated in different studies on CAP, but few reports have referred to elderly patients alone $[8,11,13]$. Previous bed confinement was identified as a prognostic factor, as was identified by RIQUeLme et al. [11], which reflects the poor basal situation of the patient. The absence of chills and altered mental state was also found, demonstrating the presentation of unspecific pneumonia [3, 26], which could lead to a delay in diagnosis and treatment. Other factors were creatinine values $\geqslant 1.4 \mathrm{mg} \cdot \mathrm{dL}^{-1}$ and $\mathrm{Pa}, \mathrm{O}_{2} / F \mathrm{I}, \mathrm{O}_{2}<200$ on admission, parameters which may indicate the severity of the pneumonia at the time of diagnosis [18, 31]. Lastly, two factors were observed during the evolution of the disease, the existence of shock and renal failure, the two most severe complications of CAP [18, 31]. Neither age nor comorbidity were associated with a worse prognosis. In a metaanalysis of prognosis and outcome of patients with CAP performed by FINE et al. [32], 11 variables were found to be associated with worse prognosis, with age not appearing among them, although several basal diseases did. In a recent study, ConTE et al. [33] developed a prognostic rule for elderly patients admitted with CAP. They found five predictors of bad prognosis as follows: presence of comorbidity, abnormal vital signs (axillary temperature $<36.1^{\circ} \mathrm{C}$, cardiac 
frequency $>110$ beats $\cdot \min ^{-1}$ and systolic arterial pressure $<90 \mathrm{mmHg}$ ), age $\geqslant 85 \mathrm{yrs}$, alteration in mental state and plasma creatinine $\geqslant 1.5 \mathrm{mg} \cdot \mathrm{dL}^{-1}$. These data should be validated in prospective studies on CAP in elderly patients but according to the present results, of the five parameters to be evaluated, only two (alteration in mental state and elevated plasma creatinine) were associated with greater mortality.

In summary, the main clinical and aetiological characteristics and the evolution and prognostic factors of a large group of elderly patients with communityacquired pneumonia have been described here.

\begin{abstract}
Acknowledgements. The authors would like to thank J. Vila from the Institut Municipal d"Investigació Médica (IMIM) de Barcelona, Barcelona, Spain, for his advice in the design of the statistical analysis and M. Niedermam from the Winthrop University Hospital, Mineola, NY, USA, for the critical review of the manuscript.

Hospitals and physicians participating in the study: 1) Hospital de Cruces, Vizcaya (R. Zalacain and V. Cabriada); 2) Hospital Clínico, Valencia (J. Blanquer and D. Pérez); 3) Hospital la Princesa, Madrid (J. Aspa and B. Nieto); 4) Hospital Clínic, Barcelona (R. Celis and A. Torres); 5) Hospital Mutua Terrassa, Barcelona (L. Esteban); 6) Hospital La Fé, Valencia (R. Menéndez); 7) Hospital Dr Peset, Valencia (R. Blanquer); 8) Hospital San Jorge, Huesca (L. Borderías); 9) Hospital Central de Asturias, Oviedo (L. Molinos); 10) Hospital de Galdakao, Vizcaya (P.P. España); 11) Hospital Arnau Vilanova, Valencia (J.A. Pérez); 12) Hospital San Millán, Logroño (M. Barrón); 13) Hospital de Xativa, Valencia (J.M. Querol); 14) Hospital Universitario, Tenerife (R. Fernández); 15) Hospital Miguel Server, Zaragoza (S. Bello); and 16) Hospital General, Albacete (M. Arévalo).
\end{abstract}

\section{References}

1. Bartlett JG, Breiman RF, Mandell LA, et al. Community-acquired pneumonia in adults: Guidelines for management. Clin Infect Dis 1998; 26: 811-838.

2. Marrie TJ. Epidemiology of community-acquired pneumonia in the elderly. Semin Respir Infect 1990; 5: 260-268.

3. Feldman C. Pneumonia in the elderly. Clin Chest Med 1999; 20: 563-573.

4. Sims RV. Bacterial pneumonia in the elderly. Emerg Med Clin North Am 1990; 8: 207-220.

5. Harper C, Newton P. Clinical aspects of pneumonia in the elderly. J Am Geriatr Soc 1989; 37: 865-872.

6. Finkelstein MS, Petkun WM, Freedman ML, et al. Pneumococcal bacteriemia in adults. Age-dependent differences in presentation and outcome. J Am Geriatr Soc 1983; 31: 19-27.

7. Riquelme R, Torres A, El-Ebiary M, et al. Communityacquired pneumonia in the elderly. Clinical and nutritional aspects. Am J Respir Crit Care Med 1997; 156: 1908-1914.
8. Venkatesan P, Gladman J, Macfarlane JT, et al. A Hospital study of community-acquired pneumonia in the elderly. Thorax 1990; 45: 254-258.

9. Metlay JP, Schulz R, Li YH, et al. Influence of age on symptoms at presentation in patients with communityacquired pneumonia. Arch Intern Med 1997; 157: 1453-1459.

10. Elbright JR, Rytel MW. Bacterial pneumonia in the elderly. J Am Geriatr Soc 1980; 28: 220-223.

11. Riquelme R, Torres A, El-Ebiary M, et al. Communityacquired pneumonia in the elderly. A multivariate analysis of risk and prognostic factors. Am J Respir Crit Care Med 1996; 154: 1450-1455.

12. Verghese A, Berk SL. Bacterial pneumonia in the elderly. Medicine 1983; 62: 271-285.

13. Rello J, Rodríguez R, Jubert P, et al. Severe communityacquired pneumonia in the elderly: Epidemiology and prognosis. Clin Infect Dis 1996; 23: 723-728.

14. Ruiz M, Ewig S, Marcos MA, et al. Etiology of community-acquired pneumonia: Impact of age, comorbidity and severity. Am J Respir Crit Care Med 1999; 160: 397-405.

15. Marrie TJ. Pneumonia in the elderly. Curr Opin Pulm Med 1996; 2: 192-197.

16. Zalacain R, Camino J, Cabriada V. Pneumonia in the elderly (Neumonía en el anciano). Arch Bronconeumol 1998; 34: Suppl. 2, 63-67.

17. Fang GD, Fine M, Orloff J, et al. New and emerging etiologies for community-acquired pneumonia with implications for therapy: a prospective multicentre study of 359 cases. Medicine 1990; 69: 307-316.

18. Dorca $\mathbf{J}$, Bello $\mathrm{S}$, Blanquer $\mathrm{J}$, et al. Diagnosis and treatment of the community acquired pneumonia (Diagnóstico y tratamiento de la neumonía adquirida en la comunidad). Arch Bronconeumol 1997; 33: 240-246.

19. Bartlett JG, Mundy LM. Community-acquired pneumonia. N Engl J Med 1995; 333: 1618-1624.

20. Mor V, Laliberte L, Morris JN, et al. The Karnofsky perfomance status scale. An examination of its reliability and validity in a research setting. Cancer 1984; 53: 2002-2007.

21. World Health Organization. International Classification of Impairment Disabilities and handicaps. A Manual of Classification Relating to Consequences of Diseases. Geneva, World Health Organization, 1980.

22. Celis R, Torres A, Gatell JM, et al. Nosocomial pneumonia. A multivariate analysis of risk and prognosis. Chest 1988; 93: 318-324.

23. Dean NC. Use of prognostic scoring and outcome assessment tools in the admission decision for community-acquired pneumonia. Clin Chest Med 1999; 20: 521-529.

24. Torres A, Serra-Batlles J, Ferrer A, et al. Severe community-acquired pneumonia. Epidemiology and prognostic factors. Am Rev Respir Dis 1991; 144: 312-318.

25. Kaplan V, Angus DC, Griffin MF, et al. Hospitalized community-acquired pneumonia in the elderly. Age and sex-related patterns of care and outcome in the United States. Am J Respir Crit Care Med 2002; 165: 766-772.

26. Fein AM, Feinsilver SH, Niederman MS. Atypical manifestations of pneumonia in the elderly. Clin Chest Med 1991; 12: 319-336.

27. Marrie TJ. Community-acquired pneumonia. Clin Infect Dis 1994; 18: 501-515. 
28. Mittl RL, Schweb RJ, Duchin JS, et al. Radiographic resolution of community-acquired pneumonia. Am J Respir Crit Care Med 1994; 149: 630-635.

29. Esposito AL. Community-acquired bacteremic pneumococcal pneumonia. Effect of age on manifestations and outcome. Arch Intern Med 1984; 144: 945-948.

30. Fine MJ, Auble TE, Yelay DM, et al. A predicition rule to identify low-risk patients with communityacquired pneumonia. N Engl J Med 1997; 336: 243-250.

31. Niederman MS, Bass JB, Campbell GD, et al.
Guidelines for the initial management of adults with community-acquired pneumonia: Diagnosis, assessment of severity, and initial antimicrobial therapy. Am Rev Respir Dis 1993; 148: 1418-1426.

32. Fine MJ, Smith MA, Carson CA, et al. Prognosis and outcomes of patients with community-acquired pneumonia. A meta-analysis. JAMA 1996; 275: 134-141.

33. Conte HA, Chen YT, Mehal W, et al. A prognostic rule for elderly patients admitted with communityacquired pneumonia. Am J Med 1999; 106: 20-28. 